\title{
Planning Cemeteries: Their Potential Contribution to Green Infrastructure and Ecosystem Services
}

\author{
Katie McClymont ${ }^{* t}$ and Danielle Sinnett ${ }^{\dagger}$ \\ Centre for Sustainable Planning and Environments, University of the West of England, Bristol, United Kingdom
}

OPEN ACCESS

Edited by:

Diogo Guedes Vidal,

Fernando Pessoa Energy,

Environment and Health Research

Unit (FP-ENAS), Portugal

Reviewed by:

Ruth Rae,

New York University, United States

Peter N. Duinker

Dalhousie University, Canada

*Correspondence:

Katie McClymont

katie.mcclymont@uwe.ac.uk

tThese authors have contributed equally to this work

Specialty section:

This article was submitted to

Urban Greening,

a section of the journal

Frontiers in Sustainable Cities

Received: 05 October 2021 Accepted: 17 November 2021 Published: 16 December 2021

Citation:

McClymont K and Sinnett D (2021) Planning Cemeteries: Their Potential Contribution to Green Infrastructure and Ecosystem Services.

Front. Sustain. Cities 3:789925. doi: 10.3389/frsc.2021.789925
Cemeteries are often included in typologies of green infrastructure features, but there has been little exploration of their role within a multifunctional network of green infrastructure. This paper uses national greenspace data to map the contribution that cemetery space makes to accessible greenspace England. In doing so we provide a more comprehensive and detailed analysis of the scale of cemetery space in contemporary settlements, finding that cemeteries provide around $4 \%$ of accessible greenspace and are particularly important in high-density urban environments. Focusing then on an in-depth analysis of an urban case study, we survey 11 cemeteries that provide accessible greenspace for neighbourhoods in Bristol, UK. This suggests that cemeteries are delivering, or have the potential, to deliver ecosystem services and therefore form an important component of green infrastructure networks, but at the same time also need to provide culturally sensitive space for burial and remembrance. Despite the rhetoric, planning policy for cemeteries is not consistent in articulating their role as green infrastructure. We highlight the opportunities for greater cultural, regulation and maintenance services to be delivered, but also the need for greater dialogue between the different players involved in the maintenance and delivery of cemeteries.

Keywords: green space, nature-based solutions, cemeteries, urban planning, burial space

\section{INTRODUCTION}

There is a gathering international body of evidence that demonstrates the myriad roles of cemeteries beyond that of bodily disposal and remembrance. These include their value as recreational spaces similar to parks, and for nature conservation. In this way, the benefits or ecosystem services they provide may overlap with those provided by green infrastructure (Nordh and Evensen, 2018), broadly defined as a multifunctional network of green and blue spaces (Sinnett et al., 2018). Authors highlight the role of cemeteries in the natural environment as well as how this intersects with human use of these spaces in cities. This is considered at further depth in our analysis, but it is here useful to introduce some headline themes. The ecosystem services delivered by green infrastructure include those related to improved health and well-being, flood risk management, improvements in soil, water and air quality, pollination and climate adaptation (Jerome et al., 2019). There is evidence that cemeteries provide a similar range of services. Assessing a range of sites across Belgium, Denmark, France, Spain, the Netherlands, Germany, Slovenia, Sweden and Italy, Długozima and Kosiacka-Beck (2020) summarise the environmental value of cemeteries. These include subcategories under the headings of vegetation, architecture, burial space and spatial context (Kowarik et al., 2016; Długozima and Kosiacka-Beck, 2020, p. 8; also see Kamran et al., 2020). They go on to argue: 
"Due to the constantly deteriorating quantity and quality of public green areas in cities, the rank of cemeteries as a public garden may increase significantly in the future. More attention should be paid to cemetery pro-ecological solutions, focusing more on shaping plant cover, which cannot be overestimated in the face of climate change" (Długozima and Kosiacka-Beck, 2020, p. 15).

Cemeteries, and other burial spaces therefore have the potential to contribute both to climate change mitigation, and to increasing quality of life for urban residents. In terms of human engagement with cemetery spaces, Lai et al. (2020) assess the restorative potential of Edinburgh's cemeteries for the urban population, finding that they offer benefits very similar to that of parks in terms of their environment. Whilst not scoring as highly on all measures, the walled nature of many cemeteries also offered a sense of calm and enclosure that several parks did not. They go on to argue; "(C)onsequently, there is a need for an integrated approach, combining local cemetery use and restoration strategies with local authority urban greenspace planning and policy" (Lai et al., 2020, p. 7).

However, the provision of these benefits needs to be balanced with what users see as acceptable within these spaces. Goh and Ching (2020) look at the views of residents of Kuala Lumpur into what activities are acceptable in the Chinese cemeteries in the city. The results accounted for social and demographic diversities and found a mixed picture with more educated people being more accepting of different activities such as sports and recreation in the cemetery spaces than the majority who did not approve of cemeteries being used for leisure-based pursuits such as arts and sports. They conclude that more detailed attention needs to be paid to the design, planning and management of cemetery spaces to reduce the likelihood of different activities causing conflict:

\footnotetext{
"the potential conflicts among different user groups should be well-thought of when considering land use zoning within cemeteries. These include prohibited and quiet zones, as well as the permissible activities in each zone by the effective usage of signage to regulate behaviour." (Goh and Ching, 2020, p. 7).
}

Such cautions are reiterated in research from South Africa, stressing the need to be attentive to the specifics of cemeteries as "urban sacred sites" as they are "often managed for different objectives to other formal urban greenspaces" (De Lacy and Shackleton, 2017, p. 2) and in Norway where, "showing respect meant that one could not sunbathe, have a picnic, drink alcohol, or sleep in the cemetery" (Swensen et al., 2016, p. 47).

In terms of planning for these spaces, Davies and Bennett (2016, p. 106) argue that cemeteries "do not fit neatly within simplistic land use zoning definitions. They are not industrial, commercial, residential nor open space." From their research in Sydney, Australia, they identify a four-fold life-cycle of cemetery evolution. After interment of bodies has finished, and a space is deemed to be full, they see visitor numbers declining and the space falling to "incremental neglect" (p. 103). Their solutions focus on grave reuse, to keep the spaces actively managed and lower demand for new sites outside of the urban area. Other authors focus more on the need for more creative interventions in urban cemeteries to enhance their beneficial role. For example, research from Scandinavia demonstrates that cemetery spaces can evolve into places of cultural encounters (Swensen et al., 2016) and that these new and evolving functions can be encouraged by city planning (Grabalov, 2018). These demonstrate the ongoing and changing role of cemetery space, and also how this is experienced differently by local populations in different contexts. The issue of who owns and manages cemetery land is important here, as is how such spaces are imaged and described by planning documents and how the management and maintenance of the space is funded (Kjøller, 2012; Nordh and Evensen, 2018; Rae, 2021).

Specifically, cemeteries and churchyards offer accessible spaces in built-up areas where there is little or no other greenspace, and limited possibilities to provide more (Evensen et al., 2017; Kaczynska, 2020), for example, Evensen et al.(2017, p. 76) argue that "(I)n densified parts of cities the cemetery may be the closest greenspace accessible for every-day use." In many, but not all cases, this is seen as a positive attribute, but cemeteries are also seen as potentially detrimental to public health, spaces which attract vagrants and anti-social behaviour, and valuable land being used for the dead rather than the living in times of housing and affordability crises (Tudor et al., 2013; Nită et al., 2014; Klaufus, 2016; Allam, 2019). The management of cemeteries, considered alongside the wider planning and infrastructure of a city, is therefore vital to ensure they can be beneficial spaces for people and for nature. There has, however, been little work that quantifies this, in terms of numbers and percentages of populations whose only accessible greenspace is a cemetery. The research in this paper addresses this gap, and uses this evidence to assess how better planning and management considering cemeteries more formally as green infrastructure could enhance the role played by cemeteries in urban green infrastructure networks.

Moreover, there is, limited research on their role in English cities in comparison to other countries, despite them often being listed as an example of greenspace or green infrastructure (e.g., Natural England, 2009; Public Health England, 2020) in policy guidance documents. Indeed, cemeteries and burial grounds are one of a few land uses changes, alongside outdoor sports and recreation, allowable in green belts in England, providing they "preserve its openness" (MHCLG, 2021). Therefore, there is a tacit assumption that cemeteries and burial space can provide some of the same functions of that of greenspace in general, that they should be conceived of, and managed in such a way so as to provide these functions. However, as this paper discusses, the way this plays out in practise at the local level is inconsistent across England.

This context raises many questions for planners and urban managers to consider when thinking about both the management of existing cemetery space in England, and also the provision of new cemeteries. The next section provides an overview of the current policy picture in England, demonstrating limited oversight or consistency. We then draw on Ordnance Survey (OS) Open Greenspace and Census data to demonstrate the extent of cemeteries as accessible greenspace, using 
Natural England's draft updated Accessible Natural Greenspace Standards (AngSt). Next, we outline the (potential) importance of cemeteries as providers of ecosystems services, drawing on previous international research which has explored this and integrating a detailed case study of Bristol: using the Neighbourhood Green Space Tool (NGST; Gidlow et al., 2012) to assess all the cemeteries in the city that enable neighbourhoods to meet AngSt. The paper demonstrates the importance of cemeteries as greenspaces, both quantitively and qualitatively, and raises suggestions and cautions about their ongoing management and the provision of new spaces.

\section{PLANNING POLICY}

From previous research, it has been demonstrated that planning policy around cemeteries is at best inconsistent and patchy, and at worst entirely absent (McClymont, 2014, 2016). From a review of statutory local planning documents in England conducted in 2014, 111 (38.1\%) had no policies or even mentions of cemeteries. In those that did mention cemeteries, the way they were was treated was mixed. Forty (13.8\%) out of 291 authorities specifically identified cemeteries as part of the green infrastructure in their area, with an additional 42 (14.4\%) listing it as green/open space which is likely to be a reflection of changing terminology, as policies were updated. This is a total of 82 out of $291(28.2 \%)$. A further $30(10.3 \%)$ authorities list cemeteries as a type of development suitable for the green belt, ${ }^{1}$ five (1.7\%) of these being in addition to a green infrastructure/open space policy which mentions cemeteries. Although this designation has relevance to the broader role and suitability of cemeteries as green infrastructure, it is beyond the scope of this specific paper. Further, some local planning documents mention the heritage value of certain cemeteries, often those containing (usually locally) listed features; with notable assets such as the Grade I listed Brookwood Cemetery in Woking, UK. Many also describe cemeteries as social or community infrastructure alongside allotments, children's play areas, public houses, places of worship and libraries. Moreover, 32 (11.0\%) list a specific development site allocated for a new cemetery, or more frequently the extension of an existing cemetery, with just 13 having other, more general principal or development metric policies to steer the allocation of new cemetery space. Of those with specific policies, either allocated sites/extensions or more general principals and metrics, 10 (3.4\%) also list cemeteries as green infrastructure or green/open space, but without always explicitly cross-referencing these different elements to their approach.

Overall, therefore, the picture of policy for cemeteries, both new and existing, is mixed and inconsistent nationally. Although several policies and plans have been updated since this comprehensive review was undertaken, from sampling 15 local authorities (5.2\%) for this study, there seems to be little overall change: there does not appear to have been any comprehensive change in the way planning authorities are seen to be dealing with

\footnotetext{
${ }^{1}$ The Green Belt is the area of undeveloped land surrounding major cities in the UK, aimed at limiting urban sprawl. Planning policy remains strong on rejecting all but exceptional development in this.
}

cemetery space. Eight of the sample had not changed at all; either using the same documents as at the time of the previous review or having updated these but not changing their policy guidance on cemeteries. Six had changed their language and focus slightly: one additionally noting the importance of a specific historic cemetery, one going from a specific policy about a specific cemetery extension to a generic green infrastructure policy, one adding cemeteries to a list of community infrastructure, as well as greenspace, one adding them to acceptable development in the green belt and one merging with other neighbouring authorities to create their plan which had a generic mention of cemeteries as open space, and the sixth adding cemeteries to the definition of green infrastructure as well as keeping policy about their suitability in the green belt. Moreover, the planning of new spaces is not systematic; national guidance mentions cemeteries twice, both in relation to being suitable exceptions to restrictions on development in the green belt (NPPF; MHCLG, 2021 paragraphs $149 \mathrm{~b}$ and 150 e, p. 43-44), and they are not mentioned in planning guidance related to green infrastructure (MHCLG, 2019). English local planning policy has to be in conformity with national guidance, and as there has been no substantive national initiatives on planning for cemeteries since 2014 it is perhaps not surprising that there has been little change in local policy over this period, with only minor changes to policy reflective of only local circumstances. Therefore, the way the spaces are defined in local plans varies across the country, and sometimes support potentially competing functions such as amenity/social value, nature conservation and heritage.

Focusing on the polices which do state that cemeteries are part of an authorities' green infrastructure or green/open space, the majority do just that and little more. Often, they are one in a list of types of spaces, and in most cases given limited consideration as outlined in the policy examples below:

\footnotetext{
"6.141 The term 'open space' can incorporate many different types of areas, ranging from formal recreation spaces like sports pitches and play areas; civic spaces like parks and ornamental gardens; functional areas like allotments, cemeteries and churchyards; linear routes such as footpaths, cycle paths, and river corridors; as well as incidental spaces like railway embankments, verges and landscaped areas within developments. Open space is normally considered to be public space." Mendip DC Local Plan Development Policy 16: Open Space and Green Infrastructure.

"10.39 Open spaces, sports and recreation facilities and children's play spaces perform important functions within communities and contribute significantly to quality of life. Open spaces can be public or private and include (but are not limited to) parks and gardens, woodlands, outdoor sports pitches, children's play space, amenity greenspace, allotments and cemeteries." Three Rivers District Council, Preferred Policy Options Consultation June 2021.
}

This is not necessarily problematic, but it does require further consideration. As cemeteries are defined differently in different areas (or entirely overlooked) there is clearly not a shared understanding of their role and function in wider built environment networks (McClymont, 2016). This means that their potential as part of a network of green infrastructure is 
not fully understood-both in terms of how they can provide additional benefits, and how they can complement the functions provided by other greenspaces.

Further, this lack of detailed understanding is compounded by a context in which England is running out of space for burials (Strangwayes-Booth, 2013; Cohen, 2019). This makes understanding their role and potential even more important. Although the majority choose cremation, there remains a consistent $25-30 \%$ of the population opting for burial, so the need for land for this must be addressed. Cemeteries were originally built in the eighteenth and nineteenth Centuries outside of built-up areas as urban churchyards overflowing with corpses were increasingly being seen as health hazards (Rugg, 2000). Due to this extra-urban setting at the time of development, many of these sites were much larger than the churchyards. Cities have now expanded to engulf these former peripheral sites, leaving them as some of the largest open spaces in (sub)urban settings. Additionally, the twin usage of cemeteries for burial and a recreational space is not entirely new, with discussion in the UK and in Scandinavia of their moral and contemplative functions (Johnson, 2008; Evensen et al., 2017) at time of inception.

Across England now, almost every local authority has at least one cemetery, although not all are accepting new burials. Further, cemeteries make up around $4 \%$ of the overall greenspace in urban England, and one which offers vital doorstep and neighbourhood access for many hundreds of thousands of people. In the analysis that follow, we explore the role of cemetery space as green infrastructure in much greater detail, mapping its extent, then going on to explore its potential and offer suggestions for planning.

\section{METHODS}

\section{Contribution of Cemeteries to Greenspace Provision}

We first examined the importance of cemeteries as part of the overall green infrastructure provision in England. To do this we used OS Open Greenspace data in ArcGIS Pro v2.4.0 to calculate the number area different types of greenspaces in each Output Area in England. The OS Open Greenspace data categorises each greenspace in Great Britain by the type (allotments, tennis courts, golf courses and other sports facilities, play spaces, playing fields, parks and gardens, religious grounds (which includes churchyards) and cemeteries), and includes the size of the greenspace (Ordnance Survey, 2021). There are 120,876 greenspaces in England of which 4,992 are cemeteries (4.1\%) (Ordnance Survey, 2021). Output Areas are the smallest geography in England for which population data are available; they comprise around 310 people with their size varying depending on population density and are nested within local authority boundaries. We used the "summarise" function in ArcGIS Pro to ascertain the area of each type of greenspace in each Output Area. We also used the Office for National Statistics (ONS) Rural-Urban Classification to examine the importance of cemeteries in urban areas. This categorises each Output Area as one of eight settlement types based on population density
(Evensen et al., 2017). This allowed us to further summarise the area of each type of greenspace in rural towns and villages, urban cities and towns, and minor and major conurbations.

\section{Potential Ecosystem Services National Analysis}

Green infrastructure is important in urban areas as it is the primary means of delivering ecosystem services, or the benefits people derive from nature. Using the framing provided by Common International Classification of Ecosystem Services (CICES) V5.1 (Haines-Young and Potschin, 2018) we next explore the potential ecosystem services that may be provided by cemeteries in England. The CICES focuses on provisioning (e.g., water for drinking, cultivated plants), regulating (e.g., mediation of wastes, flood protection) and cultural services (e.g., experiential and physical use, education), although acknowledging these are underpinned by "supporting" conditions (e.g., primary production; Haines-Young and Potschin, 2018).

We examine the potential ecosystem services provided by cemeteries through a review of the literature related to cemetery design, management and use, further spatial analysis of the OS Open Greenspace data, and surveys of a small number of cemeteries in Bristol, UK.

Building on the national analysis above we used ArcGIS Pro to calculate the number of Output Areas meeting Natural England's draft updated ANGSt (Houghton, 2021). The ANGSt set an expectation of the size of greenspace that should be provided within different distances to people's homes (Table 1; Houghton, 2021). We focused on doorstep, local and neighbourhood greenspaces as these are the greenspace types for which cemeteries appear to make the largest contribution, at around 5\%, based on an analysis of the OS Open Greenspace data (Table 1). This was used to provide some insight into the potential cultural services provided by cemeteries, as the realisation of these services is often related to access and place (Dickinson and Hobbs, 2017).

We calculated the Output Areas with cemeteries as the only greenspace meeting ANGSt criteria (Table 1). Here we used the "select by location" function in ArcGIS to identify Output Areas meeting ANGSt (i.e., a doorstep greenspace of at least 0.5 ha within $200 \mathrm{~m}$, a local greenspace of at least 2 ha within $300 \mathrm{~m}$ and a neighbourhood greenspace of at least 10 ha within $1 \mathrm{~km}$; Houghton, 2021) from the centroid of the Output Area to the boundary of the greenspace. We did this for all greenspaces, and for each greenspace type. We then used the total number of residents and the ONS Area Classification (Office for National Statistics, 2015b) from the 2011 Census (Office for National Statistics, 2017) to estimate the number of people in each Output Area and types of communities who may be dependent on cemeteries as their nearest greenspace. Classification Areas use 60 variables covering sociodemographic, housing, economic and employment data from the 2011 Census to classify Output Areas into super groups $(n=8)$, groups $(n=26)$ and subgroups $(n$ = 76) (Office for National Statistics, 2015b,c). The classifications are intended to be "illustrative" of the area, whilst recognising that there will be variation between individuals in each area 
TABLE 1 | Draft updated natural accessible greenspace standards (Houghton, 2021).

\begin{tabular}{llc}
\hline Name of criterion & Size distance criteria & Cemeteries in England meeting this size criteria \\
\hline Doorstep greenspace & At least 0.5 ha within $200 \mathrm{~m}$ & $2,430(5.4 \%$ of total) \\
Local greenspace & At least 2 ha within $300 \mathrm{~m}$ (straight line) or $500 \mathrm{~m}$ (actual walking/cycling route) & $1,147(5.7 \%)$ \\
Neighbourhood & 10 ha within $1 \mathrm{~km}$ & $213(4.6 \%)$ \\
Wider neighbourhood & At least 20 ha within $2 \mathrm{~km}$ & $42(1.5 \%)$ \\
District & 100 ha within $5 \mathrm{~km}$ & $1(0.3 \%)$ \\
Sub-regional & 500 ha within $10 \mathrm{~km}$ & 0 \\
Local nature reserves (LNRs) & LNRs of at least 1 ha per 1,000 population & - \\
\hline
\end{tabular}

(Office for National Statistics, 2015c). A full methodology for the calculation of Classification Areas is available from Office for National Statistics (2015b) and "pen pictures" are available from Office for National Statistics (2015a).

There are a number of limitations to this use of OS Greenspace data. First, as we intended only to provide an overview of the national picture, we have only calculated the distance from the centre of each Output Area to the boundary of greenspaces rather than the access points or using precise walking/cycling distances from individual homes. However, we have followed ANGSt criteria and based our analysis on straight lines. This means that the numbers of Output Areas and people are estimations rather than exact numbers. We have also used 2011 Census data and Area Classifications; the UK population has increased since this time and there are likely to have been changes in neighbourhood statistics. Some greenspaces in the OS Open Greenspace dataset have been divided where there are different uses on one site (e.g., playing fields may be co-located with a park) and this might have resulted in some greenspaces being smaller in the data than they are in reality. In addition, some cemeteries are located next to greenspaces so although the Output Area might be outside of the ANGSt distance criteria, people may be more likely to visit the adjacent greenspace. To explore some of these issues in more detail we surveyed 11 cemeteries in Bristol, UK.

\section{Surveys of Cemeteries in Bristol}

Bristol is one of eight Core Cities in England. Located in the southwest, it has an estimated population of 465,900 and is a multicultural city characterised by high levels of in-migration and student populations, and the resultant pressures of new housing delivery (Bristol City Council., 2021a). Typical of many cities in England its urban form is comprised of high density Victorian and Georgian neighbourhoods in the central areas and lower density post-World War II housing in the suburbs. To examine a selection of cemeteries that appear to be making an important contribution to accessible greenspace in Bristol we carried out surveys using the validated Neighbourhood Green Space Tool to assess greenspace quality (NGST; Gidlow et al., 2012). The cemeteries were selected based on the spatial analysis as those that appeared to be the only greenspace meeting ANGSt criteria for at least one Output Area. Surveys were conducted in daylight during August and September 2021 by at least one researcher and scores discussed. Two cemeteries were visited by both researchers to ensure internal agreement between the scoring. Although the NGST does not measure ecosystem services directly, it is useful to assess the extent to which the spaces are likely to support cultural services (e.g., accessibility, facilities, and amenities), regulating services (e.g., presence of natural features, and usage) and provisioning services (usage and types of natural features). The scoring in the survey was supplemented with handwritten notes of observations related to ecosystem services where possible (e.g., presence of fruit trees), as well as reviewed literature. The scoring sheet used is provided as Supplementary Material. Each cemetery was assessed according to access (number of access points; pedestrian crossings, short cuts; number of pathways, quality of pathways), recreation facilities (number of play facilities, grass pitches, hard courts, skateboard ramps and other pieces of equipment/facilities for different activities; quality of equipment for different activities, amount of open space, and quality of open space), amenities (provision/quality of seating, litter bins, dog bins, and lighting), natural features (provision/quality of grass, trees/shrubs/plants, flowers/flower beds; water/water features) and incivilities (extent of litter, alcohol debris, drug paraphernalia, graffiti, broken glass, vandalism, dog mess, and noise). Each item was given a score according to Gidlow et al. (2012) and weighted scores calculated out of 100 (access = $18 \%$, recreation facilities $=16 \%$, amenities $=22 \%$, natural features $=20 \%$, and incivilities $=24 \%$ ). The primary and secondary purposes (formal/informal recreation, access/green corridor, biodiversity/conservation, general amenity space, and cemetery/crematoria), usage (suitability for sport, informal games, walking, child's play, and conservation/biodiversity) and whether the cemetery was current open for new burials were also recorded (see Supplementary Material).

\section{RESULTS AND DISCUSSION Contribution of Cemeteries to Greenspace Provision}

The area of cemeteries in each local authority in England varies in absolute terms, as a proportion of total area and area of greenspace. Except for the Isles of Scilly and the City of Westminster, all local authorities have some cemetery space, varying from 0.28 ha in the City of London to 183.5 ha in Birmingham. In terms of proportion of area, the local authority with the lowest proportion of cemetery space is West Lancashire $(0.006 \%)$, and the greatest is the London Borough of Newham 
(3.6\%). Similarly, the proportion of greenspaces that are cemetery space range from $0.24 \%$ in West Lancashire to $31.4 \%$ in the London Borough of Kensington and Chelsea although the proportion in Newham is $31.3 \%$. On average, there are 30 ha of cemetery space across English local authorities, occupying $0.3 \%$ of local authority area and $3.7 \%$ of greenspace area.

Turning to the Rural-Urban Classifications, rural areas have the greatest area of greenspace in absolute terms, but it occupies the smallest proportion of their area at 1.1\% (Table 2). In contrast, the area of greenspaces in minor and major conurbations is smaller at 8,647 and 71,715 ha, respectively, but they occupy a greater proportion of land at 8.9 and $11.9 \%$, respectively. A similar pattern is seen in cemeteries, which make up a greater proportion of greenspaces in urban vs. rural areas; $3.8 \%$ in urban cities and towns to $4.9 \%$ in major conurbations (Table 2).

Although not as substantial as most of other types of greenspace, cemeteries contribute around $4 \%$ of the total greenspace area in English towns and cities, and are ubiquitous in urban environments. They also usually offer public access for informal recreation, without the need for fees or memberships that may be necessary for playing fields, sports facilities and allotments. They are an important part of green infrastructure features and therefore have the potential to deliver ecosystem services for urban populations.

\section{Potential Ecosystem Services Cultural Services}

Cultural ecosystem services include those associated with physical, experiential, intellectual, representative, spiritual and symbolic interactions (Haines-Young and Potschin, 2018).
Many of these interactions, for example, for physical activity, education and relaxation, require physical access to the site. Therefore, the ANGSt criteria have been used to examine the accessibility of cemeteries and assess their potential contribution to cultural services.

\section{National Analysis}

Overall, the proportion of the population living in an Output Area meeting the criteria for doorstep, local and neighbourhood greenspaces is $43.4,45.1$, and $58.6 \%$, respectively. Across these categories, playing fields, parks and gardens, and sports facilities tend to provide the greatest access (Table 3), with cemeteries providing doorstop, local and neighbourhood greenspaces to $3.3,4.3$, and $7.4 \%$ of the population, respectively (Table 3 ). However, turning to the people living in areas where the only publicly accessible greenspace meeting these criteria are cemeteries, we see that cemeteries provide access to doorstep, local and neighbourhood greenspaces for around $2 \%$ of the population, or $1.18,1.09$, or $1.39 \mathrm{~m}$ people, respectively, based on the 2011 population (Table 4). It is particularly at the level of neighbourhood greenspaces (i.e., $>10$ ha) that cemeteries appear to provide the greatest contribution to ensuring neighbourhoods meet the Natural England ANGSt criteria. Historically, cemetery provision in the UK tended to rely on large municipal cemeteries located beyond the built-up area in Victorian and Georgian times (Rugg, 2000), and whilst these areas also often provide large parks they are often smaller than 10 ha (1,572 over 10 ha, compared with 6,765 over $0.5 \mathrm{ha}$ ) or may be more than $1 \mathrm{~km}$ from people's homes.

Using Area Classifications reveals interesting patterns about the types of communities for whom cemeteries may be an

TABLE 2 | Area of greenspaces in rural and urban areas in England.

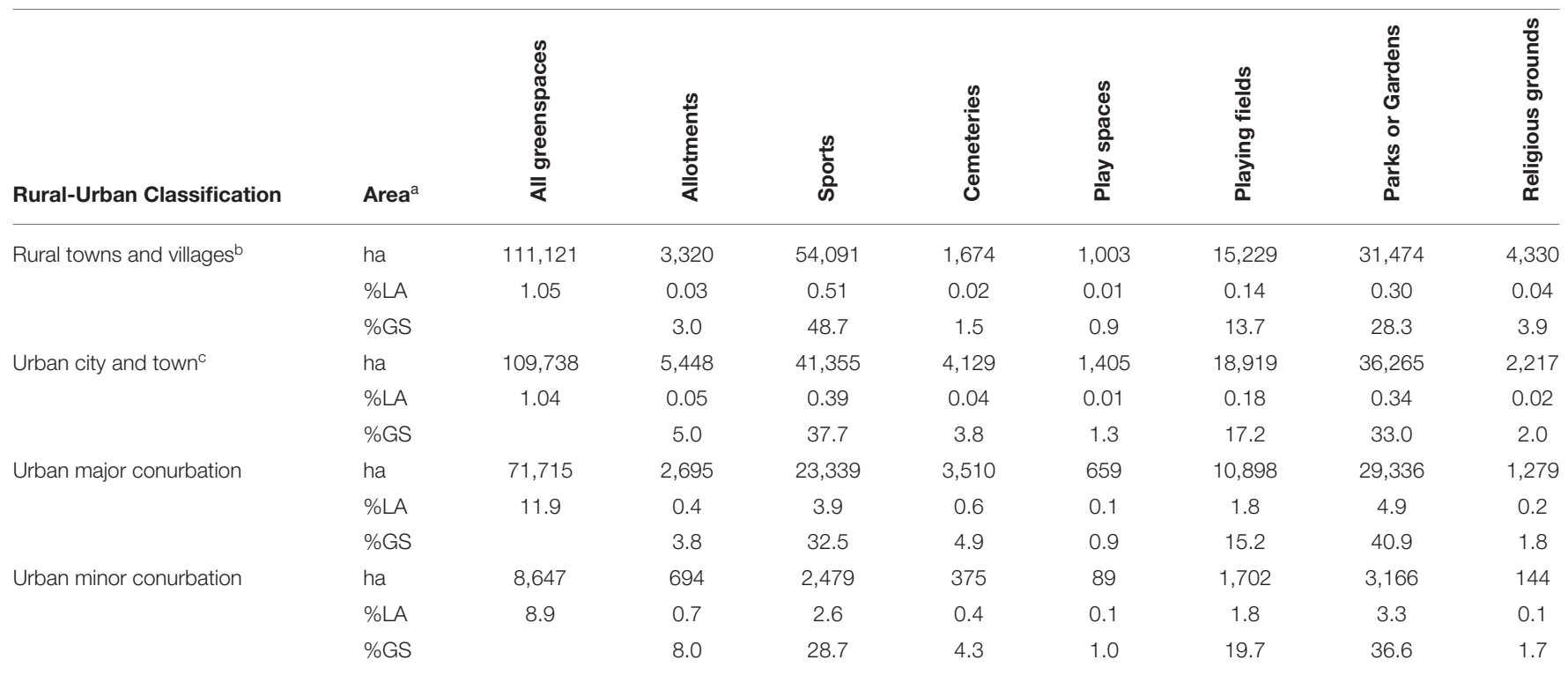

a \% LA = percentage area of greenspace in the local authority, \%GS = percentage area of each type of greenspace of the total greenspace.

${ }^{b}$ Comprised of: Rural town and fringe; Rural town and fringe in a sparse setting; Rural village and dispersed; Rural village and dispersed in a sparse setting.

${ }^{c}$ Comprised of: Urban city and town; Urban city and town in a sparse setting. 


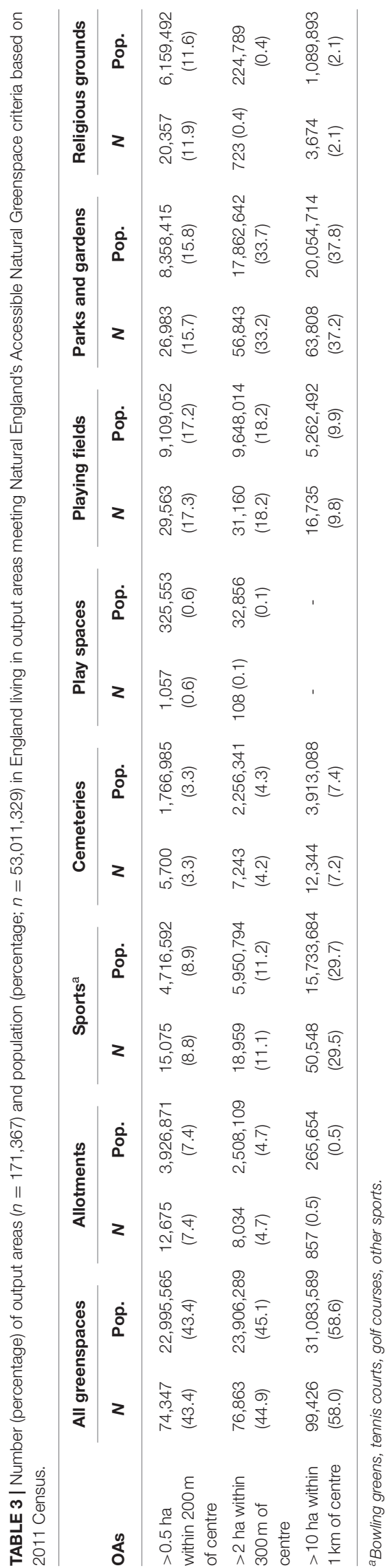

important type of greenspace (Figure 1). Here, the overall proportion of people for whom their only greenspace is a cemetery masks important variations between groups. For example, it appears that cemeteries are much less important for rural communities than for their urban and suburban counterparts. Students Around Campus appear to be particularly dependent on cemeteries, although many university campuses have green areas which might not be represented in the OS Open Greenspaces dataset. Access to the larger neighbourhood greenspace appear to be especially variable, with as much as 4$6 \%$ of the population dependent on cemeteries. Whilst some of these groups, including Aspiring and Affluent (Figure 1) may have access to private gardens or be able to afford to travel further to access nature, other groups may not be so fortunate. Most of these classifications are characterised by high density housing, dominated by flats and terraced housing, often with greater than average proportions of children (Office for National Statistics, 2015c). Groups including Challenged Diversity, Constrained Flat Dwellers, Challenged Terraced Workers, and Migration and Churn all have relatively high numbers of Output Areas with only cemeteries as their neighbourhood greenspaces (Figure 1). In addition to high density, terraced housing, Challenged Terrace Workers, Challenged Diversity, Constrained Flat Dwellers and Migration and Churn have higher levels of unemployment, lower car ownership, and, in the latter two cases, higher proportions of flats and social rent (Office for National Statistics, 2015c) meaning they may not be able to readily access private gardens or travel to alternative greenspaces. This is also the case for neighbourhoods classified as Ethnicity Central (Aspirational Techies, Ethnic Family Life, Endeavouring Ethnic Mix and Ethnic Dynamics), and to a lesser extent, Multicultural Metropolitans (Rented Family Living, Challenged Asian Terraces, Asian Traits), and these areas have greater than average levels of ethnic diversity (Office for National Statistics, 2015c) (Figure 1). Because of this ethnic and religious diversity, it is important to develop a deeper understanding of perspectives on the suitable uses for these spaces and how or if they vary for different groups (see Goh and Ching, 2020; Maddrell et al., 2021).

\section{Cemeteries in Bristol}

Turning to the surveys of cemeteries in Bristol, we selected 11 cemeteries out of a total of nineteen, that spatial analysis revealed were the only greenspace meeting ANGSt criteria for at least one Output Area (Figure 2). These were assessed using the NGST across five domains: access, recreational facilities, amenities, natural features and incivilities.

Looking across the total scores for the quality of the cemeteries as greenspaces range for 29.9 out of 100 at the Wesleyan Burial Ground and 71.6 for Arnos Vale. These cemeteries have very different histories, contexts, management and ownership. The Wesleyan Burial Ground appears to have been adjacent to a non-conformist chapel that has subsequently been redeveloped for housing and the entrance points to the burial space removed (Figure 3A). Unlike Anglican (Church of England) burial grounds which are protected under the 1853 Burial Act (Historic England, 2020), there is no duty for public authorities 
TABLE 4 | Number (percentage) of output areas $(n=171,367)$ and population (percentage; $n=53,011,329)$ in England with cemeteries as the only accessible greenspace.

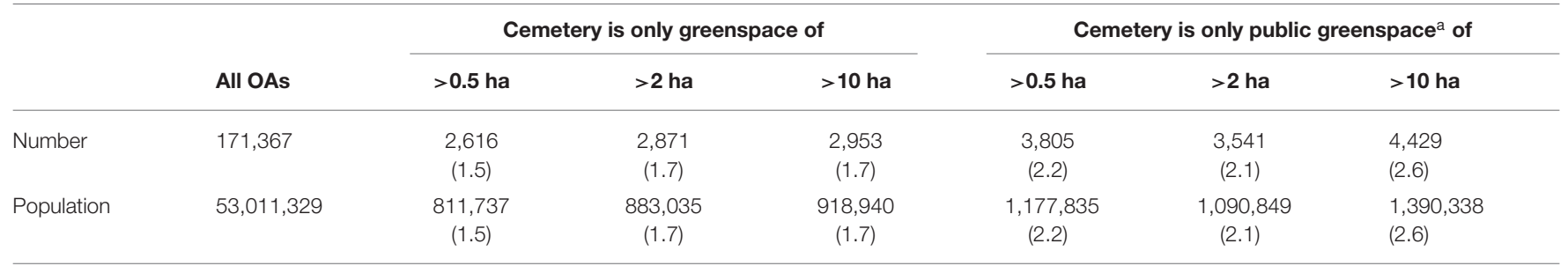

assumed to be play spaces, playing fields and parks and gardens.

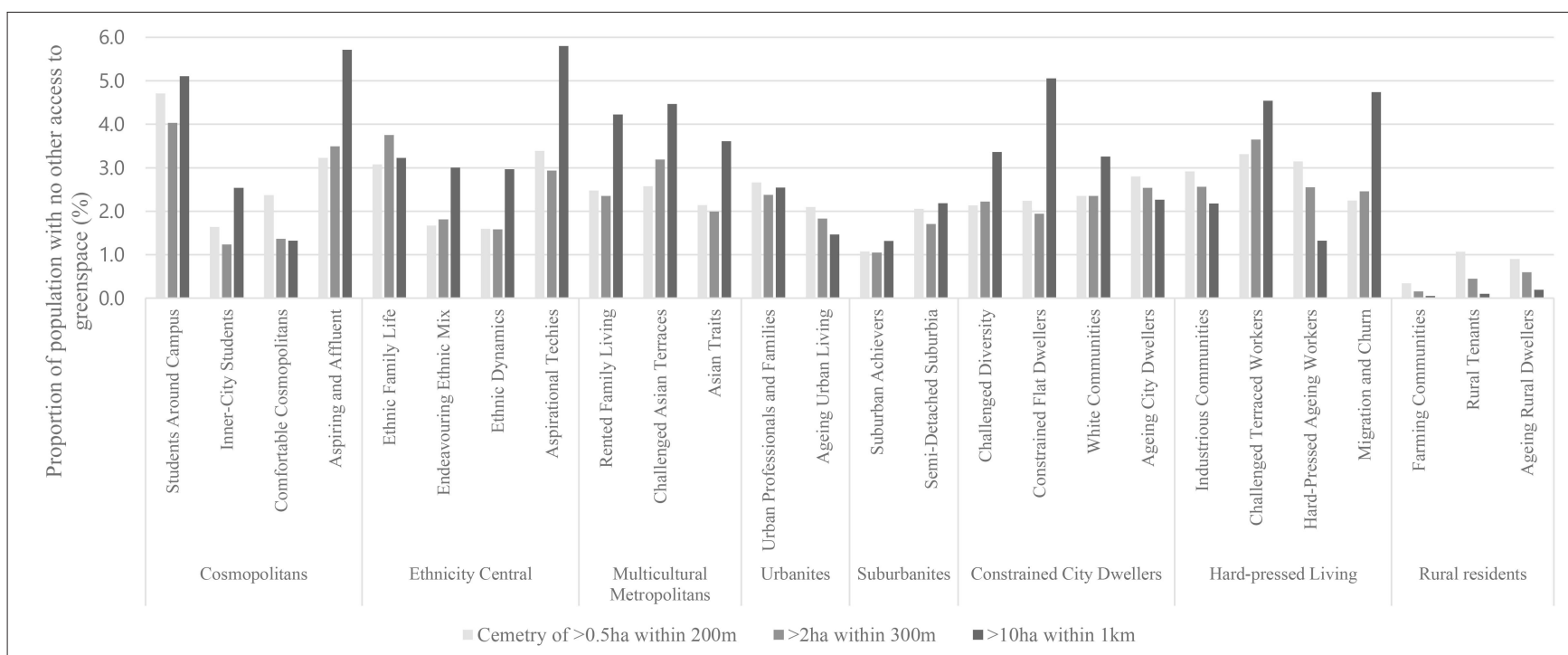

FIGURE 1 | Percentage of the population in social classification groups that live in output areas where the only greenspace meeting ANGSt is a cemetery based on the 2011 English Census.

to take on the management and maintenance of burial grounds of other faiths/denominations once they are no longer used.

In terms of access, the only inaccessible site is the Wesleyan Burial Ground, which is surrounded by high, stone walls so it was not possible to gain access to the site, but it appeared that the vegetation had been allowed to overgrow (Figure 3A), potentially providing a resource for nature conservation. The other cemeteries we explored are all open to the public at least during daylight hours, but there is variation between them. For example, the older burial spaces in Birdcage Walk (Figure 3B), St. John's Churchyard and St. John's Burial Ground provide green corridors, in the latter case providing connectivity to a green active travel route, the Malago Greenway. In contrast, Shirehampton Cemetery has minimal access points, and severs the adjacent housing from other facilities, including a primary school. Greenbank Cemetery was functioning with two formal entry/exit points, despite its original design having six gates (Figure 3C). Similarly, South Bristol Cemetery, a more modern facility, which includes a crematorium and is the only site currently taking new burials, is in a relatively suburban location, surrounded by a railway line, main road and offices, although it is accessible from nearby housing via a public park.
In contrast, Arnos Vale is a large cemetery that is overtly managed by a charitable trust for amenity use, for example, through the provision of signage, café, toilets, seating, and tours (Figures 3D,E).

Whilst surveying we observed many people using some of the cemeteries (Birdcage Walk, St. John's Burial Ground, St. John's Churchyard, Arnos Vale, Avon View, and Canford, Greenbank) as general amenity spaces and access routes. Activities included walking, sitting, chatting, eating a picnic, dog walking, socialising, cycling and playing, echoing the findings from Oslo of Evensen et al. (2017) and Swensen et al. (2016). Those with fewer entrances and less accessibility to surrounding neighbourhoods, for example Shirehampton, Henbury and South Bristol, appeared to be less used as amenity spaces. Except for South Bristol Cemetery, these cemeteries are dominated by older burials and therefore they might be expected to be less visited by those connected to the burials.

The scoring (Table 5) reveals obvious gaps in the availability of recreation facilities across all sites, with the exception of Arnos Vale. This is unsurprising given that the sites are cemeteries, many still partially in use for burial in family plots or for ash scattering. Where sites do tend to score in this category 


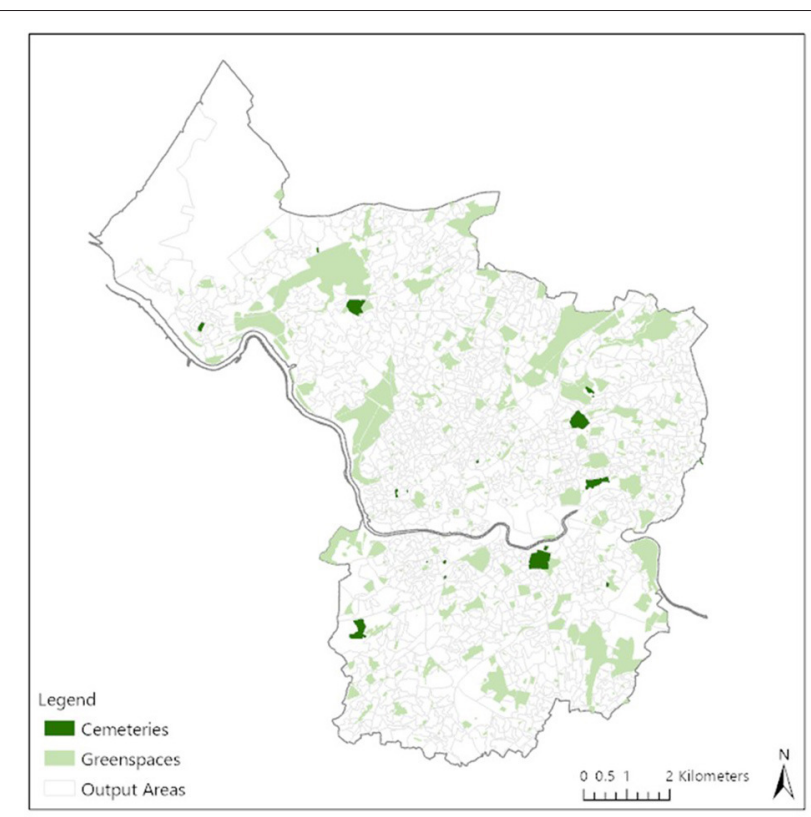

FIGURE 2 | Location of greenspaces and cemeteries in Bristol, UK with cemeteries surveyed in this study labelled (Contains public sector information licenced under the Open Government Licence v3.0; Contains National Statistics data ${ }^{(C)}$ Crown copyright and database right 2021; Contains OS data ${ }^{(C)}$ Crown copyright and database right 2021).

is in the provision of open space; most of the cemeteries we surveyed did include some, often relatively small, areas of open grass (Figures 3F,G). The scoring of amenities is more mixed, with those cemeteries, such as Arnos Vale, St. John's Burial Ground, St. John's Churchyard, and Birdcage Walk (Figure 3), which are managed predominantly as amenity space, scoring better for features such as seating and litter bins. Similarly, these older cemeteries include more variety of natural features, particularly trees, shrubs and areas explicitly managed for nature conservation (see below), whereas those with more recent burials seem to be maintained as more formal spaces with short mowing and few other types of vegetation other than trees (Figure $3 \mathbf{H}$ ).

Interestingly, and perhaps in contrast to amenity spaces in general, the cemeteries scored very highly in relation to incivilities with little evidence of litter, vandalism and dog mess. Whilst some of the cemeteries we surveyed (Birdcage Walk, St. John's Burial Ground, and St. John's Churchyard) are managed by the local authority as greenspaces, the others are managed by the Cemeteries and Crematoria Services (a separate part of the local authority); organisations which have overlapping concerns but are likely to have differences in priority/focus (see Kjøller, 2012). Given the cuts to parks maintenance in recent years, and the sensitive nature of cemetery spaces, it may be the cemeteries have higher levels of maintenance than greenspaces and are closed during the night. Although there was evidence of cuts to funding, for example in closed public toilets at Avonview Cemetery (Figure 3I).

Overall, the cemeteries we surveyed score relatively well on the measure of greenspace quality that we used. Many have diverse vegetation types, including mature trees, reasonable access to the surrounding neighbourhoods, provide some amenities in the form of seating and litter bins, and lack obvious incivilities. The relative importance, or acceptability of cemeteries being actively managed in this way unsurprisingly relates to their age and the related number of visits to the space being directly related to the personal remembrance of a deceased person. Sites such as Greenbank Cemetery seem to be in a transitional stage between amenity and remembrance-the majority of users observed were dog walking, cutting through the space or taking young children out to look at nature. Moreover, active management for nature has been seen as well as past attempts to bring the chapel buildings into community use (Know Your Bristol, n.d) in a way which would not be fitting in a cemetery primarily focused on burial and bereavement.

Nordh et al. (2017) make a clear case for the important cultural services provided by cemeteries in their discussion of their restorative potential. They outline the tranquil and spiritual environment they provide, alongside their heritage value and space for human encounters with nature. Their research into Norwegian cemeteries demonstrates that only about a quarter of people entering the sites they focused upon were there for anything directly related to a grave; the other three quarters were pursuing more recreational activities, or using the space as a green corridor.

\footnotetext{
"The visitors' descriptions implied that it was the combination of nature, culture, and history, as well as respect for the deceased and others visiting graves, that made the cemetery different from other green spaces in the city. This made it a place that supported restoration, and provided them with a place for relaxation, reflection, and contemplation in their everyday environment" (Nordh et al., 2017, p. 116).
}

The potential contribution of cemeteries to cultural ecosystems services is therefore notable, and is something that has wide reach. Cemeteries are not synonymous with other greenspaces but offer their own contribution to the urban landscape. This contribution is one which needs careful management over time and within any given settings. The heritage and recreational value of these spaces is recognised by their inclusion in planning polices for green and community infrastructure, but only at a headline level. Joint guidance issued by English Heritage and Natural England (2007) (also see Historic England, 2020) discusses some of the ways in which cemeteries can be managed for nature and for heritage, as do related publications for churchyards (Cocke, 2012). A wider understanding which encompasses the benefits of cemeteries as green infrastructure, as well as acknowledging their life cycles could draw on these insights and provide valuable guidance for planners in assessing the role of cemetery space in a wider network as well as offering deeper understanding on which to base planning for new cemeteries. In addition, those cemeteries now managed as amenity greenspaces provide spaces for exercise such as walking and contribute to active travel routes which are associated with beneficial impacts on physical and mental health (Hunter et al., 2019). 


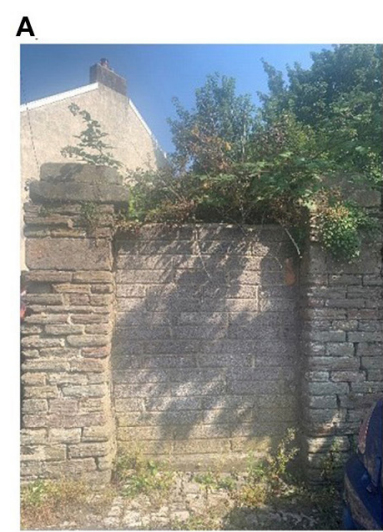

\section{D}

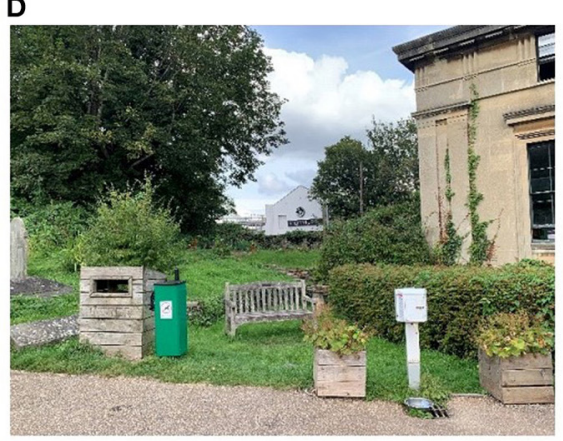

$\mathbf{F}$

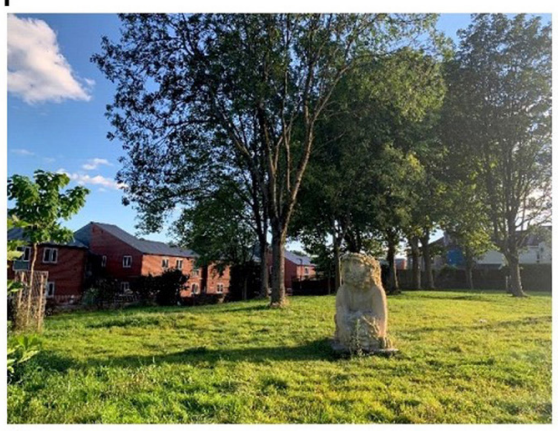

H

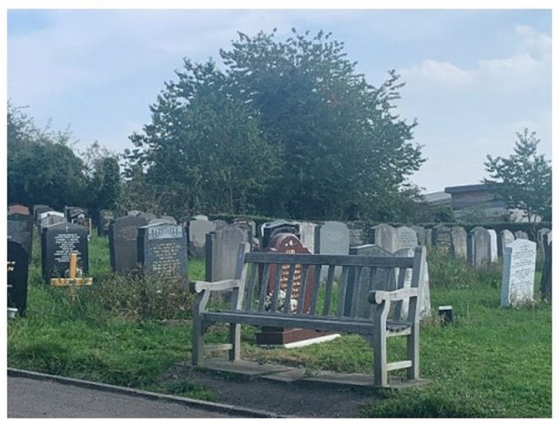

B

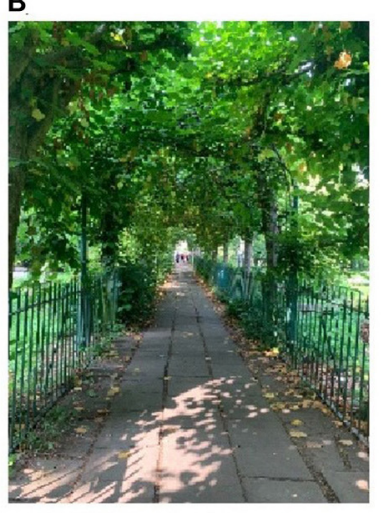

E

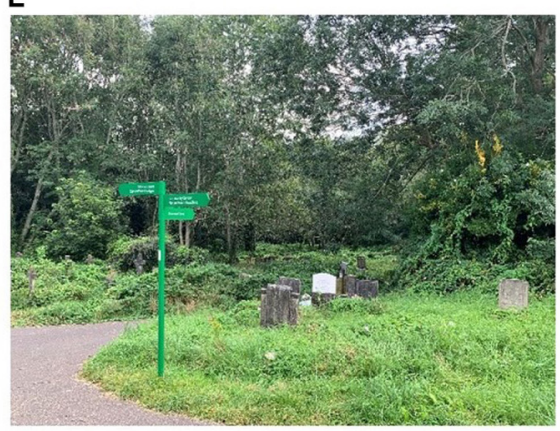

G

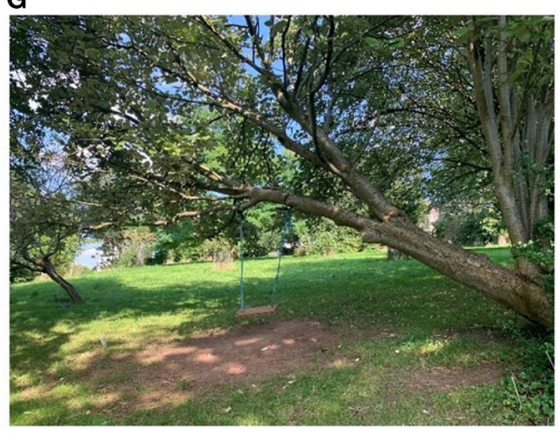

I

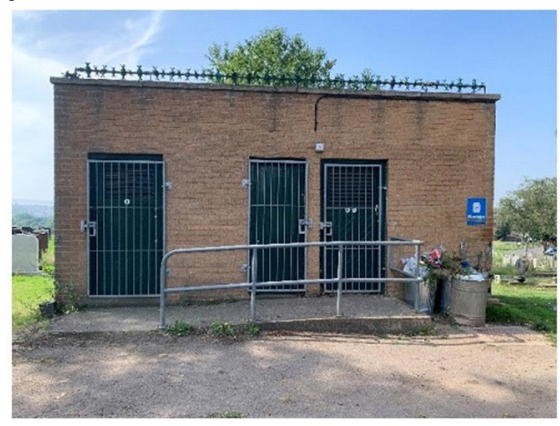

FIGURE 3 | Examples of access and amenities in (A) blocked access at Wesleyan Burial Ground, (B) Birdcage Walk, (C) path to Malago Greenway at St. John's Burial Ground, (D) litter bins and seating and (E) signage at Arnos Vale, (F) sculpture on open space at John's Churchyard, (G) informal tree swing and open space at St. John's Burial Ground, (H) formal graves and seating and (I) closed public toilets at Avonview Cemetery. 
TABLE 5 | Quality of cemeteries as greenspaces in Bristol using the Neighbourhood Green Space Tool (Gidlow et al., 2012).

\begin{tabular}{|c|c|c|c|c|c|c|c|c|c|c|}
\hline \multirow[t]{2}{*}{ Site } & \multirow{2}{*}{$\begin{array}{l}\text { Area } \\
\text { (ha) }\end{array}$} & \multirow{2}{*}{$\begin{array}{l}\text { Currently in } \\
\text { use for new } \\
\text { burial }\end{array}$} & \multirow{2}{*}{$\begin{array}{l}\text { Primary }(\mathrm{P}) \text { and } \\
\text { secondary }(\mathrm{S}) \\
\text { purpose }\end{array}$} & \multirow[t]{2}{*}{ Usage, suitability for } & \multicolumn{5}{|c|}{ Total domain score (maximum; weighting) } & \multirow[b]{2}{*}{ Total score $/ 10 c$} \\
\hline & & & & & $\begin{array}{c}\text { Access } \\
(11 ; 18 \%)\end{array}$ & $\begin{array}{c}\text { Recreation facilities } \\
(25 ; 16 \%)\end{array}$ & $\begin{array}{l}\text { Amenities } \\
(16 ; 22 \%)\end{array}$ & $\begin{array}{c}\text { Natural features } \\
\quad(16 ; 20 \%)\end{array}$ & $\begin{array}{l}\text { Incivilities } \\
\text { (14; 24\%) }\end{array}$ & \\
\hline $\begin{array}{l}\text { Arnos Vale } \\
\text { Cemetery }\end{array}$ & 18.43 & Partial & $\begin{array}{l}\text { P: General amenity } \\
\text { space (GAS), S: } \\
\text { Cemetery/crematorium }\end{array}$ & $\begin{array}{l}\text { Walking, } \\
\text { conservation/biodiversity }\end{array}$ & 8 & 8 & 9 & 9 & 14 & 71.6 \\
\hline $\begin{array}{l}\text { Wesleyan Burial } \\
\text { Grounda }^{\text {a }}\end{array}$ & 0.50 & No & $\begin{array}{l}\text { P: Cemetery, S: } \\
\text { Biodiversity/conservation }\end{array}$ & Conservation/biodiversity & 0 & 0 & 0 & 4 & 14 & 29.9 \\
\hline $\begin{array}{l}\text { St John's Burial } \\
\text { Ground }\end{array}$ & 0.54 & No & $\begin{array}{l}\text { P: GAS, S: } \\
\text { Access/green corridor }\end{array}$ & $\begin{array}{l}\text { Walking, } \\
\text { conservation/biodiversity, } \\
\text { child's play }\end{array}$ & 6 & 5 & 2 & 8 & 12 & 51.5 \\
\hline $\begin{array}{l}\text { Avon View } \\
\text { Cemetery }\end{array}$ & 8.73 & Partial (infill) & P: Cemetery, S: GAS & $\begin{array}{l}\text { Walking, } \\
\text { conservation/biodiversity }\end{array}$ & 5 & 2 & 2 & 3 & 14 & 39.9 \\
\hline Birdcage Walk & 1.06 & No & $\begin{array}{l}\text { P: Access/green } \\
\text { corridor, S: GAS }\end{array}$ & $\begin{array}{l}\text { Walking, } \\
\text { conservation/biodiversity, } \\
\text { child's play }\end{array}$ & 4 & 6 & 6 & 7 & 14 & 55.2 \\
\hline $\begin{array}{l}\text { Greenbank } \\
\text { Cemetery }\end{array}$ & 12.99 & Partial & P: Cemetery, S: GAS & $\begin{array}{l}\text { Walking, } \\
\text { conservation/biodiversity }\end{array}$ & 5 & 4 & 2 & 7 & 13 & 48.5 \\
\hline Canford Cemetery & 11.71 & Partial & P: Cemetery, S: GAS & Walking, conservation & 6 & 6 & 6 & 8 & 14 & 60.7 \\
\hline Henbury Cemetery & 0.58 & Partial & P: Cemetery, S: GAS & Conservation/biodiversity & 3 & 3 & 5 & 3 & 13 & 39.9 \\
\hline $\begin{array}{l}\text { Shirehampton } \\
\text { Cemetery }\end{array}$ & 2.15 & Partial & P: Cemetery, S: GAS & Conservation/biodiversity & 2 & 1 & 2 & 3 & 13 & 32.8 \\
\hline $\begin{array}{l}\text { St. John's } \\
\text { Churchyard }\end{array}$ & 0.57 & No & $\begin{array}{l}\text { P: GAS, S: } \\
\text { Access/green corridor }\end{array}$ & $\begin{array}{l}\text { Walking, } \\
\text { conservation/biodiversity, } \\
\text { child's play }\end{array}$ & 6 & 4 & 3 & 7 & 14 & 53.1 \\
\hline $\begin{array}{l}\text { South Bristol } \\
\text { Cemetery }\end{array}$ & 11.00 & Yes & P: Cemetery & $\begin{array}{l}\text { Walking, } \\
\text { conservation/biodiversity }\end{array}$ & 2 & 3 & 5 & 5 & 13 & 42.7 \\
\hline
\end{tabular}

${ }^{a}$ Majority (0.495 ha) outside Bristol's boundary in neighbouring South Gloucestershire. 


\section{Regulation and Maintenance Services}

Regulation and maintenance concerns ecosystem services such as mediation of wastes, including degradation, nuisances (e.g., smell, noise, and visual impacts), protection from storms and floods, habitat protection (e.g., pollination and seed dispersal), regulating soil and air quality, and temperature. The cemeteries we observed in Bristol all had the potential to contribute to these services. They included predominantly permeable surfaces, which can reduce surface water runoff in urban areas (Jerome et al., 2019; Figure 3). Vegetation, but particularly trees, also contribute to the reduction of urban heat island and mitigate air pollution including particulate matter (Sinnett, 2021). Most of the cemeteries we surveyed, particularly the older spaces or older burial areas within cemeteries such as Avonview, had relatively high tree cover (Figures 4A-D). There were signs that these trees are an important feature of the cemetery, for example, Avonview has an active tree planting campaign and there were signs that infill burials had been placed to minimise tree damage (Figure 4E). Two of the cemeteries, Arnos Vale and South Bristol, also have areas for woodland and natural burials. Although all burials are likely to provide degradation services through the breakdown of remains, natural burials purport to minimise the negative environmental impacts associated with the presence of coffins and artefacts (Clayden et al., 2018).

As mentioned above, there were signs that some of the older cemeteries were being managed for nature. These included borders deliberately left overgrown (e.g., St. John's Burial Ground), signage promoting the biodiversity value of the site at Arnos Vale (Figures 4E,F) and "bug hotels" at Greenbank Cemetery. A sparrowhawk and deer were sighted in the visit to Henbury Cemetery; and although the space was not visibly being managed for nature, its sheltered location and connections to wider green infrastructure networks (Blaise Estate and beyond) appear to incidentally provide habitats. The spaces also contained a mix of tree species and vegetation types, with bird song being a common feature in the older, more overgrown spaces (e.g., Birdcage Walk and Arnos Vale; Figures 4G,H). The lack of more formal maintenance around graves in these spaces is more likely to provide a habitat for wildlife than short mown grasses observed at some cemeteries and in many greenspaces.

Specifically because of their sacred, and therefore protected qualities, it is noted that cemeteries can offer enhanced areas of species protection in a range of settings. Kamran et al. (2020) argue that "graveyards (in Pakistan) represent a less disturbed location for plant species and an ideal place for natural conservation" (Kamran et al., 2020, p. 1154). Kamran et al.'s (2020) study demonstrates that several species are only found inside graveyards or are much more populous there: because they are deemed as sacred spaces, the inhabitants remain protected. Kowarik et al. (2016) demonstrate the ecosystems services provided by one of the largest Jewish cemeteries in Europe, Weißensee cemetery in Berlin. They explore how "their size, habitat heterogeneity, and habitat continuity" (Kowarik et al., 2016, p. 68) supports urban biodiversity. The specific usage of cemetery space, as tranquil, sacred spaces, as opposed to the more active uses of parks and playing fields, also offers particular benefits. In researching the scope for cemeteries to support tree cover provision of cemeteries in Halifax, Nova Scotia, Quinton et al. (2020, p. 2) state that:

\begin{abstract}
"The low-impact uses of cemeteries reduce the potential for soil compaction, and this, combined with the lack of overhead utility wires, vehicular traffic, and impervious surfaces suggest that cemeteries may be ideal locations for the survival of young trees. The lack of built infrastructure within cemeteries, other than monuments and the occasional building, indicates that there may be open space suitable for expanding tree populations" (Quinton et al., 2020, p. 2).
\end{abstract}

Trees in cemeteries can therefore provide benefits for water management, shade and cooling as well as recreation. With cities, including our case study city of Bristol, looking to plant more trees as part of climate change adaptation (Bristol City Council., 2021b), there is the need to consider more fully the role cemeteries may have in supporting this.

\section{Provisioning Services}

Provisioning services are concerned with the role of ecosystems in food and timber production, and the supply of drinking water (Haines-Young and Potschin, 2018). As with flood and storm protection, cemeteries are likely to contribute to water supply due to their permeable surfaces. The habitats they provide may also provide increased pollination, thereby indirectly contributing to food production. Although it is unlikely that cemeteries would be used for food production, we did observe that a small community orchard has been established at St. John's Burial Ground (Figures 4B,E). Similarly, ash die back has resulted in a number of trees being felled at Arnos Vale and their timber is being used to make small household items such as light pulls, which are sold in the shop to raise funds for the management of the space.

In summary, we found that cemeteries are a minor, but important part of the overall greenspace provision in England. They provide accessible greenspaces for around 2\% of the population, over 1 million people based on the 2011 population, often in relatively high density and/or disadvantaged neighbourhoods, who would not otherwise meet the AngSt requirements for doorstep, local or neighbourhood greenspace. Our modest survey of eleven cemeteries offering this access in Bristol found evidence that these spaces are offering a range of cultural, regulation and maintenance, and provisioning services. We now draw on these cemeteries and the literature to consider opportunities for cemeteries to increase their ecosystem service provision.

\section{OPPORTUNITIES TO INCREASE ECOSYSTEM SERVICE DELIVERY FROM CEMETERIES}

This study has shown that cemeteries both offer a range of ecosystems services at present and have the scope to increase their offer through thoughtful management and maintenance. 
A

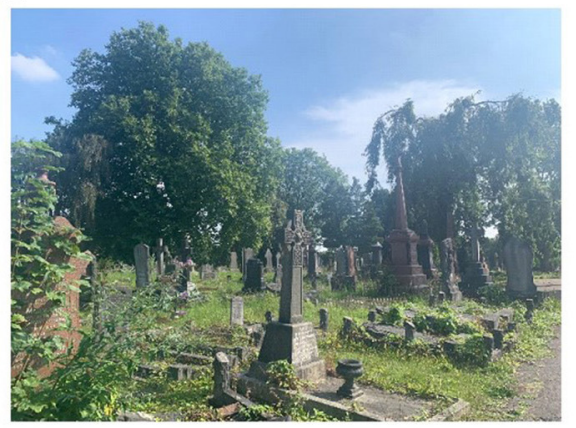

c

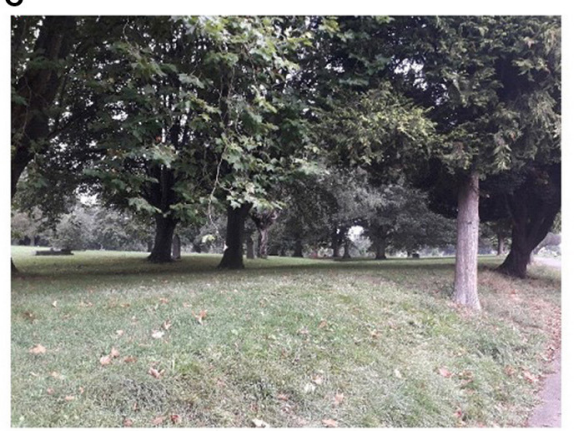

E

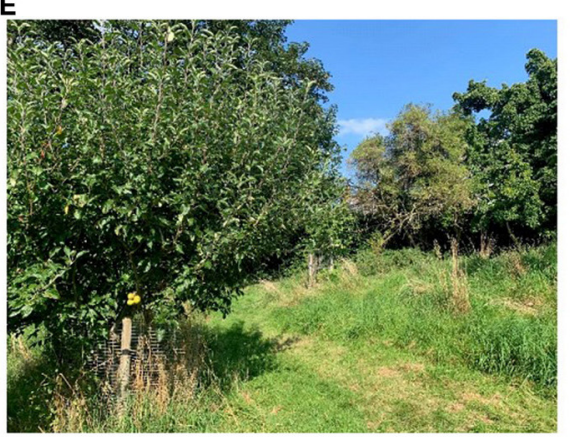

G

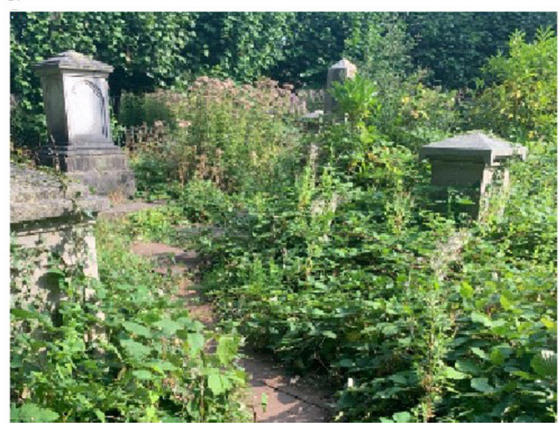

B

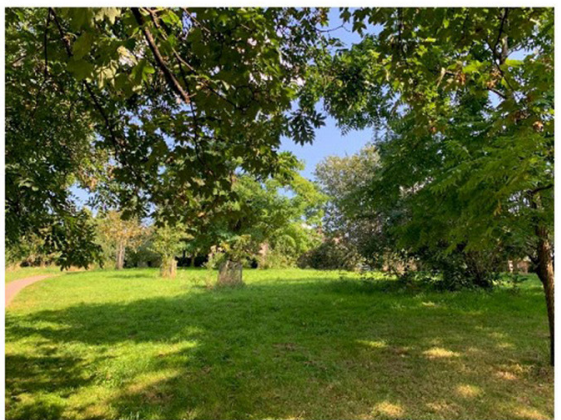

D

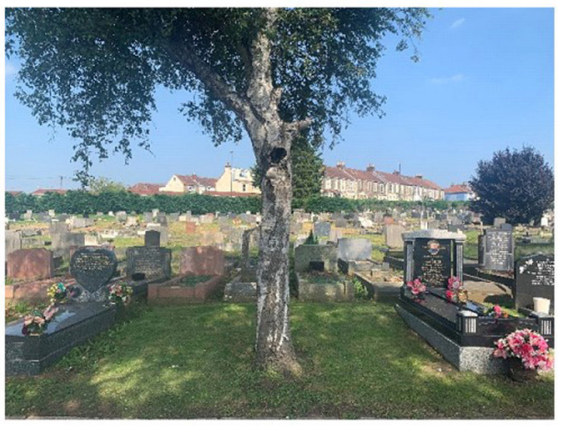

F

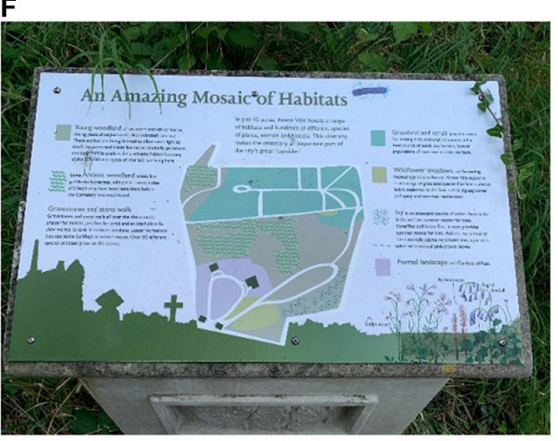

H

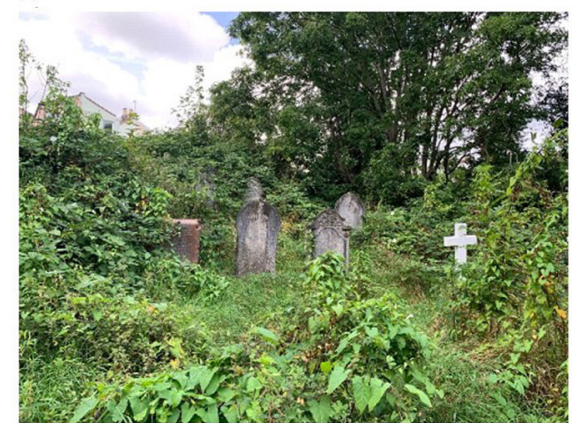

FIGURE 4 | Examples of trees at (A) Avonview Cemetery, (B) St. John's Burial Ground and (C) Greenbank, (D) infill burial avoiding damage to trees at Avonview Cemetery, (E) overgrown areas at St John's Burial Ground, (F) interpretative signage at Arnos Vale, and overgrown graves at (G) Birdcage Walk and (H) Arnos Vale.

\section{Cultural Services}

Cemeteries' distinctive qualities lead them to offer spaces more suitable for quiet reflection than noisy sports or play, and as well as this widening of the cultural offer provided by urban greenspaces, they provide natural habitats in different ways than other types of space.
The age and current use of space classified as cemeteries in the dataset has a large bearing on its acceptability and positive functioning as green infrastructure. As discussed above, the older closed churchyards scored highly as they are managed as greenspaces, albeit quiet and small additions to a wider landscape. Arnos Vale Cemetery, although developing options for bodily 
disposal including ash scattering and a new area of "natural burial," scored most highly, demonstrating the ability of sites to positively incorporate both burial and green infrastructure functions. To really assess the more widespread potential for cemeteries in England to deliver ecosystem services, and benefit the local populations for whom they are the only greenspace accessible at a certain distance, a better understanding of their place in a lifecycle (Davies and Bennett, 2016) is needed so that their management and maintenance can be focused on their primary users at any given time. Greenbank Cemetery appeared on a cusp of change in its lifecycle, with high levels of recreational users observed as opposed to people tending graves. However, a sensitive engagement with a range of current users would be needed to really understand the meaning and acceptability of different activities, or changes to management and maintenance in this site.

There are many simple opportunities to enhance the cultural services provided by cemeteries. Whilst it may not be appropriate to include play facilities or other recreational features in cemeteries, the contrast between those cemeteries that scored lowest and highest on the NGST provide some suggestions as to where small changes may be appropriate. These include improving access, for example, by reopening closed entrances or creating new ones to allow cemeteries to be used for active travel or accessed within shorter walking distances to homes. Improving the number and quality of paths within the cemeteries, increasing seating and providing lighting and litter bins could also be achieved relatively simply. The cemeteries we surveyed scored well on absence of incivilities, but efforts towards increasing accessibility and attractiveness for recreational uses may require increased maintenance.

\section{Regulation and Maintenance Services}

Cemeteries are likely to provide some regulation and maintenance services, such as flood risk management, climate regulation and air quality improvement, by virtue of their high vegetation cover and permeable surfaces. Most of the cemeteries we visited had good tree cover, which is reported to be more beneficial for reducing temperatures and air pollution than grass and other shorter vegetation (Sinnett, 2021). There is therefore an opportunity for increasing tree cover in cemeteries and perhaps selecting larger species that are reported to deliver more ecosystem services, but that are often more challenging to plant in street settings. Given that many cities now have targets to increase canopy cover, which they may struggle to meet within existing planting capacities and land availability (Walters and Sinnett, 2021), cemeteries may offer an appropriate location to plant additional trees.

Some of the cemeteries surveyed for this study incorporated features to increase biodiversity, these included areas of unmown vegetation, dead wood and "bug hotels." Again, here some simple (and potentially cost-effective) changes to management practises such as leaving grass unmown, or introducing wildflower meadows, shrub and tree species beneficial to pollinators could increase the pollination services provided by cemeteries (Baldock, 2020). These may not be acceptable in burial areas, as they can be perceived as "messy" (Hoyle et al., 2017) but could be incorporated into marginal areas. As well as pollination services, the trees in cemeteries also provide an opportunity to introduce bat and bird boxes, especially given that human disturbance may be reduced in cemeteries compared with other public greenspaces.

\section{Provisioning Services}

Cemeteries are probably unlikely to make a large contribution to the delivery of provisioning services. Other than their permeable surfaces allowing water infiltration, there are likely to be concerns regarding the use of spaces for burial and food production. However, one older cemetery did provide orchard trees and it may be that in older sites, fruit trees could be planted, which would also diversify the tree species composition in urban areas.

\section{Balancing Different Functions}

However, designing and managing cemeteries for ecosystem service delivery must be done without losing sight of the primary function of cemetery space: a place for the hygienic and culturally appropriate disposal of human bodily remains. In this, it is necessary to promote a deeper understanding of what this means for different faith and cultural groups, and how assumptions of "normal" or "acceptable" are shaped by dominant forces which maintain neo-colonial patterns of inclusion and exclusion (Beebeejaun et al., 2021; Maddrell et al., 2021). The ability to complete timely and appropriate rituals and practises around death are vital to full senses of belonging and inclusion for all people, with assurances that burial places will be maintained and operated in ways which perpetuates this. For example, dogs in cemeteries is a contentious topic: not only for those whose religion requires graves to rest undisturbed by people or animals, but also because of fear and anger about defecation more widely. However, for others, a space to walk a dog is a key aspect of a neighbourhood greenspace.

Such issues need to be considered when thinking through the role cemeteries play in established green infrastructure networks, and their potential role in new developments. Thoughtful design which consults and engages with established communities and faith/cultural groups should be able to accommodate these needs (see Evensen et al., 2017). This reiterates the need for planning to be proactive and considered in its treatment of new cemeteries: seeing these spaces as simultaneously cultural, sacred and green infrastructure. This raises important questions about management and accessibility and as Swensen et al., 2016 claim, the need to "find a balance between under and over-management of common spaces that enables multiple uses without placing valuable assets at risk" (Swensen et al., 2016, p. 49).

\section{CONCLUSIONS}

Without systematic or consistent consideration of both need and provision for cemetery space, or a more nuanced understanding of the different roles played by different cemeteries, churchyards and burial grounds across the urban landscape opportunities may be missed for more integrated, beneficial spaces, contributing 
both the green infrastructure networks and the cultural cohesion of places. Planners and those managing and promoting both cemeteries and green infrastructure need to be attentive to the potentially competing needs of this "multifunctional" space (Woodthorpe, 2011) and engage in dialogue with relevant parties to ensure that by meeting the targets of one set of indicators, it does not compromise another. To achieve this systematically across England, this is likely to require national policy guidance as well as increased funding for staff time to undertake such dialogue, however, work such as this aims to promote the benefits of a more joined-up approach. In addition, the spatial analysis demonstrates that cemeteries play an important role in the provision of doorstep, local and neighbourhood greenspace, therefore contributing to the benefits provided by such space for a range of people. Nationally, this is particularly important for groups who may not have the money or ability to access space elsewhere, nor have access to private gardens. Planners should ensure that cemeteries are included in spatial assessments of green infrastructure networks and strategies for their longterm planning. This could include more detailed analysis of their accessibility to different populations, their contribution to ecological and active travel networks and flood risk management. Green infrastructure strategies could also include specific proposals for increasing ecosystem service delivery in cemeteries and the opportunities they provide for achieving wider objectives, for example for tree canopy cover or biodiversity. New cemeteries could also be specifically designed to incorporate features for ecosystem service delivery, particularly considering the longevity of cemetery space, and planners have a role in ensuring that cemeteries are recognised for their potential contribution as part of a network of multifunctional green infrastructure at inception.

\section{REFERENCES}

Allam, Z. (2019). The city of the living or the dead: on the ethics and morality of land use for graveyards in a rapidly urbanised world. Land Use Policy 87:104037. doi: 10.1016/j.landusepol.2019.104037

Baldock, K. (2020). Opportunities and threats for pollinator conservation in global towns and cities, Current Opinion in Insect. Science 38, 63-71 doi: 10.1016/j.cois.2020.01.006

Beebeejaun, Y., McClymont, K., Maddrell, A., Mathijssen, B., and McNally, D. (2021). Death in the peripheries: planning for minority ethnic groups beyond "the city." J. Plan. Educ. Res. [Epub ahead of print]. doi: 10.1177/0739456X211043275

Bristol City Council. (2021a). The Population of Bristol - September 2021. Available online at: https://www.bristol.gov.uk/documents/20182/33904/ Population\$+\$of\$+\$Bristol\$+\$September\$+\$2021.pdf/e6cb7ac8-278c-c351$9 \mathrm{dcc}-07 \mathrm{a} 83 \mathrm{fb} 4 \mathrm{fe} 23 ? \mathrm{t}=1632843439676$ (accessed Nov 26, 2021).

Bristol City Council. (2021b). One Tree Per Child. Available online at: https://www. bristol.gov.uk/museums-parks-sports-culture/one-tree-per-child (accessed Nov 26, 2021).

Clayden, A., Green, T., Hockey, J., and Powell, M. (2018). Cutting the lawn - Natural burial and its contribution to the delivery of ecosystem services in urban cemeteries. Urban Forest. Urban Green. 33, 99-10. doi: 10.1016/j.ufug.2017.08.012

Cocke, T. (2012). The Churchyards Handbook. Norwich: Church House Publishing.
Although we do not claim that this picture is representative of the situation across cities and towns in England, it is likely to have raised issues which will be repeated elsewhere. Cemeteries are currently playing a role as green infrastructure, but precisely what role this is, whether this can be enhanced and whether in so doing this interferes with their purpose of sacred spaces of remembrance needs further consideration. This includes questions of maintenance. When new cemetery space is required, the identification of suitable locations needs to proactively balance these environmental and social/cultural needs.

\section{DATA AVAILABILITY STATEMENT}

The raw data supporting the conclusions of this article will be made available by the authors, without undue reservation.

\section{AUTHOR CONTRIBUTIONS}

KM and DS: conceptualisation, methodology, data collection and curation, formal analysis, writing, and review and editing. All authors contributed to the article and approved the submitted version.

\section{SUPPLEMENTARY MATERIAL}

The Supplementary Material for this article can be found online at: https://www.frontiersin.org/articles/10.3389/frsc.2021. 789925/full\#supplementary-material

Cohen, D. (2019). Britain's Burial Crisis - And How to Solve it. Financial Times Magazine Life and Arts. Available online at: https://www.ft.com/content/ 88bdc01c-29a0-11e9-a5ab-ff8ef2b976c7 (accessed Nov 26, 2021).

Davies, P. J., and Bennett, G. (2016). Planning, provision and perpetuity of deathscapes. Past and future trends and the impact for city planners. Land Use Policy 55, 98-107. doi: 10.1016/j.landusepol.2016. 03.029

De Lacy, P., and Shackleton, D. (2017). Aesthetic and spiritual ecosystem services provided by urban sacred sites. Sustainability (Basel, Switzerland). 9:1628. doi: $10.3390 /$ su9091628

Dickinson, D. C., and Hobbs, R. J. (2017). Cultural ecosystem services: characteristics, challenges and lessons for urban green space research. Ecosyst. Serv. 25, 179-194. doi: 10.1016/j.ecoser.2017. 04.014

Długozima, A., and Kosiacka-Beck, E. (2020). How to enhance the environmental values of contemporary cemeteries in an urban context. Sustainability 12:2374. doi: $10.3390 /$ su12062374

English Heritage and Natural England. (2007). Paradise Preserved: An Introduction to the Assessment, Evaluation, Conservation and Management of Historic Cemeteries. Available online at: https://thegardenstrust.org/wpcontent/uploads/2016/11/EH-Paradise-Preserved-2007-1.pdf (accessed Nov 26, 2021).

Evensen, K. H., Nordh, H., and Skaar, M. (2017). Everyday use of urban cemeteries: a Norwegian case study. Landscape Urban Plan. 159, 76-84. doi: 10.1016/j.landurbplan.2016.09.019 
Gidlow, C. J., Ellis, N. J., and Bostock, S. (2012). Development of the neighbourhood green space tool (NGST). Landscape Urban Plan. 106, 347-358. doi: 10.1016/j.landurbplan.2012.04.007

Goh, H. C., and Ching, F. E. (2020). Acceptable use of Chinese cemeteries in Kuala Lumpur as perceived by the city's residents. Urban Forest Urban Green. 55:126837. doi: $10.1016 /$ j.ufug.2020.126837

Grabalov, P. (2018). Public life among the dead: Jogging in Malmö cemeteries. Urban Forest. Urban Green. 33, 75-79. doi: 10.1016/j.ufug.2018. 01.027

Haines-Young, R., and Potschin, M. B. (2018). Common International Classification of Ecosystem Services (CICES) V5.1 and Guidance on the Application of the Revised Structure. Available online at: www.cices.eu (accessed Nov 26, 2021)

Historic England. (2020). Caring for Heritage. Available online at: https:// historicengland.org.uk/advice/caring-for-heritage/cemeteries-and-burialgrounds/management/ (accessed Nov 26, 2021).

Houghton, J. (2021). "Green infrastructure standards framework," in Presentation to the Green Infrastructure Standards Conference. (2021). [Epub ahead of print].

Hoyle, H., Jorgensen, A., Warren, P., Dunnett, N., and Evans, K. (2017). "Not in their front yard" The opportunities and challenges of introducing perennial urban meadows: A local authority stakeholder perspective. Urban Forest. Urban Green. 25, 139-149. doi: 10.1016/j.ufug.2017.05.009

Hunter, R., Cleland, C., Cleary, A., Droomers, M., Wheeler, B. W., Sinnett, D., et al. (2019). Environmental, health, wellbeing and equity effects of urban green space interventions: a meta-narrative evidence synthesis. Environ. Int. 130:104923. doi: 10.1016/j.envint.2019.104923

Jerome, G., Sinnett, D., Burgess, S., Calvert, T., and Mortlock, R. (2019). A framework for assessing the quality of green infrastructure in the built environment in the UK. Urban Forest. Urban Green. 40, 174-182. doi: 10.1016/j.ufug.2019.04.001

Johnson, P. (2008). The modern cemetery: a design for life. Soc. Cult. Geogr. 9 , 777-790, doi: 10.1080/14649360802383154

Kaczynska, M. (2020). The church garden as an element improving the quality of city life - a case study in Warsaw. Urban Fores. Urban Green. 54:126765. doi: 10.1016/j.ufug.2020.126765

Kamran, S., Khan, S. M., Ahmad, Z., Ur Rahman, A., Iqbal, M., Manan, F., et al. (2020), The role of graveyards in species conservation and beta diversity: a vegetation appraisal of sacred habitats from Bannu, Pakistan. J. Forest. Res. 31, 1147-1158. doi: 10.1007/s11676-019-00893-1

Kjøller, C. P. (2012). Managing green spaces of the deceased: characteristics and dynamics of Danish cemetery administrations. Urban Forest. Urban Green. 11, 339-348. doi: 10.1016/j.ufug.2012.02.002

Klaufus, C. (2016). "The dead are killing the living": spatial justice, funerary services, and cemetery land use in urban Colombia. Habitat Int. 54, 74-79. doi: 10.1016/j.habitatint.2015.11.032

Know Your Bristol. Know your Greenbank. Available online at: https:// knowyourbristol.blogs.bristol.ac.uk/on-the-move/exploring-co-production/ ultralocal/ (accessed Nov 26, 2021).

Kowarik, I., Buchholz, S., von der Lippe, M., and Seitz, B. (2016). Biodiversity functions of urban cemeteries: evidence from one of the largest Jewish cemeteries in Europe. Urban Forest. Urban Green. 19, 68-78. doi: 10.1016/j.ufug.2016.06.023

Lai, K. Y., Sarkar, C., Sun, Z., and Scott, I. (2020). Are greenspace attributes associated with perceived restorativeness? A comparative study of urban cemeteries and parks in Edinburgh, Scotland. Urban Forest. Urban Green. 53:126720. doi: 10.1016/j.ufug.2020.126720

Maddrell, A., McNally, D., Beebeejaun, Y., McClymont, K., and Mathijssen, B. (2021). Intersections of (infra)structural violence and cultural inclusion: the geopolitics of minority cemeteries and crematoria provision. Trans. Inst. Br. Geogr. 46:1-14. doi: 10.1111/tran.12437

McClymont, K. (2014). Planning for the end? Cemeteries as planning's 'skeleton in the closet'. Town Country Plan. 83:282-285.

McClymont, K. (2016). "That eccentric use of land at the top of the hill': cemeteries and stories of the city. Mortality 21, 378-396, doi: $10.1080 / 13576275.2016 .1151865$

MHCLG (2019). Planning Guidance: Natural Environment. Available online at: https://www.gov.uk/guidance/natural-environment\#green-infrastructure (accessed Nov 26, 2021).
MHCLG (2021). National Planning Policy Framework. Available online at: https://www.gov.uk/government/publications/national-planning-policyframework\$-\$2 (accessed Nov 26, 2021).

Natural England (2009). Green Infrastructure Guidance NE176. Available online at: https://www.gov.uk/government/publications/national-planningpolicyframework\$-\$2 (accessed Nov 26, 2021).

Nită, M. R., Iojă, I. C., Rozylowicz, L., Onose, D. A., and Tudor, A. C. (2014). Land use consequences of the evolution of cemeteries in the Bucharest Metropolitan Area. J. Environ. Plan. Manag. 57, 1066-1082. doi: 10.1080/09640568.2013.815607

Nordh, H., and Evensen, K. H. (2018). Qualities and functions ascribed to urban cemeteries across the capital cities of Scandinavia. Urban Forest. Urban Green. 33, 80-91. doi: 10.1016/j.ufug.2018.01.026

Nordh, H., Evensen, K. H., and Skår, M. (2017). A peaceful place in the city-A qualitative study of restorative components of the cemetery. Landscape Urban Plan. 67, 108-117. doi: 10.1016/j.landurbplan.2017.06.004

Office for National Statistics (2015a). 2011 Rural/Urban Classification. Available online at: https://www.ons.gov.uk/methodology/geography/ geographicalproducts/ruralurbanclassifications/2011ruralurbanclassification (accessed Nov 26, 2021).

Office for National Statistics (2015b). Methodology Note for the 2011 Area Classification for Output Areas. ONS. Available online at: https://www.ons. gov.uk/methodology/geography/geographicalproducts/areaclassifications/ 2011 areaclassifications/methodologyandvariables (accessed Nov 26, 2021).

Office for National Statistics (2015c). Radial Plots for the 2011 Area Classification for Output Areas. ONS. Available online at: https://webarchive.nationalarchives. gov.uk/ukgwa/20160105160709/http://www.ons.gov.uk/ons/guide-method/ geography/products/area-classifications/ns-area-classifications/ns-2011-areaclassifications/pen-portraits-and-radial-plots/radial-plots-oa.pdf (accessed Nov 26, 2021).

Office for National Statistics, National Records of Scotland; Northern Ireland Statistics and Research Agency. (2017). 2011 Census Aggregate Data. London: UK Data Service (Edition: February 2017).

Ordnance Survey (2021). OS Open Greenspace Technical Specification. Ordnance Survey. Available online at: https://www.ordnancesurvey.co.uk/businessgovernment/tools-support/open-map-greenspace-support (accessed Nov 26, 2021).

Public Health England (2020). Improving Access to Greenspace: A New Review for 2020. Available online at: https://assets.publishing.service.gov.uk/government/ uploads/system/uploads/attachment_data/file/904439/Improving_access_to_ greenspace_2020_review.pdf (accessed Nov 26, 2021).

Quinton, J. M., Duinker, P. N., Steenberg, J. W. N., and Charles, J. D. (2020). The living among the dead: cemeteries as urban forests, now and in the future. Urban Forest. Urban Green. 48:126564. doi: 10.1016/j.ufug.2019.126564

Rae, R. A. (2021). Cemeteries as public urban green space: management, funding and form. Urban Forest Urban Green. 61:127078. doi: 10.1016/j.ufug.2021.127078

Rugg, J. (2000). Defining the place of burial: what makes a cemetery a cemetery? Mortality 5, 259-275. doi: 10.1080/713686011

Sinnett, D. (2021). "Mitigating air pollution and the urban heat island effect: the roles of urban trees," in: The Routledge Handbook of Urban Ecology, 2nd Edn. eds. I. Douglas, D. Goode, M. Houck, and D. Maddox (Routledge: Abingdon), 639-648.

Sinnett, D., Calvert, T., Smith, N., Burgess, S., and King, L. (2018). The translation and use of green infrastructure evidence. Proc. ICE Water Manag. 171, 99-109. doi: 10.1680/jwama.16.00112

Strangwayes-Booth, A. (2013). Burial Space in England Could Run out in 20 Years. BBC News, Avalilable online at: https://www.bbc.co.uk/news/uk-24283426 (accessed Nov 26, 2021).

Swensen, G., Nordh, H., and Brendalsmo, J. (2016). A green space between life and death - a case study of activities in Gamlebyen Cemetery in Oslo, Norway. Norsk Geografisk Tidsskrift 70, 41-53. doi: 10.1080/00291951.2015.1102169

Tudor, C. A., Iojă, I. C., Hersperger, A., and Pătru-Stupariu, I. (2013). Is the residential land use incompatible with cemeteries location? Assessing the attitudes of urban residents. Carpathian J. Earth Environ. Sci. 8, 153-116.

Walters, M., and Sinnett, D. (2021). Achieving tree canopy cover targets: a case study of Bristol, UK. Urban Forest. Urban Green. 65:7296. doi: 10.1016/j.ufug.2021.127296 
Woodthorpe, K. (2011). Sustaining the contemporary cemetery: implementing policy alongside conflicting perspectives and purpose. Mortality 16, 259-276. doi: $10.1080 / 13576275.2011 .586125$

Conflict of Interest: The authors declare that the research was conducted in the absence of any commercial or financial relationships that could be construed as a potential conflict of interest.

Publisher's Note: All claims expressed in this article are solely those of the authors and do not necessarily represent those of their affiliated organizations, or those of the publisher, the editors and the reviewers. Any product that may be evaluated in this article, or claim that may be made by its manufacturer, is not guaranteed or endorsed by the publisher.

Copyright (c) 2021 McClymont and Sinnett. This is an open-access article distributed under the terms of the Creative Commons Attribution License (CC BY). The use, distribution or reproduction in other forums is permitted, provided the original author(s) and the copyright owner(s) are credited and that the original publication in this journal is cited, in accordance with accepted academic practice. No use, distribution or reproduction is permitted which does not comply with these terms. 